\title{
The Large-Scale Dynamical Response of Clouds to Aerosol Forcing $\mathscr{A}$
}

\author{
BRIAN SODEN AND EUI-SEOK CHUNG \\ Rosenstiel School of Marine and Atmospheric Science, University of Miami, Miami, Florida
}

(Manuscript received 26 January 2017, in final form 1 June 2017)

\begin{abstract}
Radiative kernels are used to quantify the instantaneous radiative forcing of aerosols and the aerosolmediated cloud response in coupled ocean-atmosphere model simulations under both historical and future emission scenarios. The method is evaluated using matching pairs of historical climate change experiments with and without aerosol forcing and accurately captures the spatial pattern and global-mean effects of aerosol forcing. It is shown that aerosol-driven changes in the atmospheric circulation induce additional cloud changes. Thus, the total aerosol-mediated cloud response consists of both local microphysical changes and nonlocal dynamical changes that are driven by hemispheric asymmetries in aerosol forcing. By comparing coupled and fixed sea surface temperature (SST) simulations with identical aerosol forcing, the relative contributions of these two components are isolated, exploiting the ability of prescribed SSTs to also suppress changes in the atmospheric circulation. The radiative impact of the dynamical cloud changes is found to be comparable in magnitude to that of the microphysical cloud changes and acts to further amplify the interhemispheric asymmetry of the aerosol radiative forcing. The dynamical cloud response is closely linked to the meridional displacement of the Hadley cell, which, in turn, is driven by changes in the cross-equatorial energy transport. In this way, the dynamical cloud changes act as a positive feedback on the meridional displacement of the Hadley cell, roughly doubling the projected changes in cross-equatorial energy transport compared to that from the microphysical changes alone.
\end{abstract}

\section{Introduction}

Feedbacks associated with the coupled response of the circulation and clouds are recognized as the primary cause of the intermodel spread in climate sensitivity (e.g., Stevens and Bony 2013). Estimates of the globalmean cloud feedback range from neutral to strongly positive in response to global surface warming arising from $\mathrm{CO}_{2}$ forcing (e.g., Soden and Held 2006; Soden et al. 2008; Zelinka et al. 2013, 2016; Vial et al. 2013; Chung and Soden 2015). Realistic forcing scenarios include not only anthropogenic greenhouse gases (mainly $\mathrm{CO}_{2}$ ) but also aerosols that scatter and absorb a substantial portion of incoming solar radiation. These direct radiative impacts of aerosols can be further amplified or dampened because aerosols act as cloud condensation nuclei and thus alter cloud albedo and cloud lifetime

Supplemental information related to this paper is available at the Journals Online website: https://doi.org/10.1175/JCLI-D-170050.s1.

Corresponding author: Dr. Brian Soden, b.soden@miami.edu (e.g., Twomey 1977; Albrecht 1989; Penner et al. 1992; Rotstayn and Penner 2001; Lohmann et al. 2010; Myhre et al. 2013; Zelinka et al. 2014). Since emissions of anthropogenic aerosols are independent of changes in global-mean surface temperature, in situ modification of cloud microphysical properties by aerosols provides an additional mechanism for inducing cloud changes independent of surface-driven feedback processes (i.e., socalled rapid adjustments or indirect forcings; e.g., Gregory et al. 2004; Gregory and Webb 2008; Andrews and Forster 2008; Colman and McAvaney 2011; Zelinka et al. 2013; Vial et al. 2013; Kamae et al. 2015; Chung and Soden 2015). Differences in the representation of these aerosol-cloud interactions, therefore, further amplify the uncertainty in how clouds respond to anthropogenic forcings.

The source regions of anthropogenic aerosols emissions are mainly located in the extratropics of the Northern Hemisphere ( $\mathrm{NH})$, and the residence time of aerosols in the atmosphere is very short compared to that for well-mixed greenhouse gases. Consequently, anthropogenic aerosols exert a hemispherically asymmetric radiative forcing. This asymmetry modifies the 
temperature gradient between the hemispheres, which, in turn, induces changes in the large-scale atmospheric circulation (e.g., Ming and Ramaswamy 2011; Bollasina et al. 2011; Rotstayn et al. 2013; Hwang et al. 2013; Ocko et al. 2014; Allen et al. 2015).

In this study we demonstrate how these aerosolinduced changes in the atmospheric circulation lead to additional changes in clouds. Anthropogenic aerosols, therefore, not only induce local changes in cloud microphysical properties by acting as cloud condensation nuclei but also result in nonlocal cloud response through changes in the large-scale atmospheric circulation. This dynamical cloud response to aerosol forcing reflects a robust link between clouds and the circulation that further enhances the impact of aerosols on climate.

\section{Data and methodology}

\section{a. Previous studies}

The instantaneous radiative forcing (IRF) measures the change in radiative flux caused by an imposed change in aerosol emissions where all other climate variables are held constant. In contrast, the effective radiative forcing (ERF) also includes radiative flux perturbations arising from aerosol-induced changes in cloud properties (i.e., indirect effects or adjustment). Given that absorbing aerosols may induce changes in the static stability of the atmosphere that in turn affect clouds (i.e., semidirect effects), semidirect effects are likely to account for part of the ERF from anthropogenic aerosols. Previous studies have estimated ERF by performing two atmosphere-only simulations with the same sea surface temperatures; aerosols are set to preindustrial levels for the control run and present-day aerosol emissions are used for the perturbed run (e.g., Rotstayn and Penner 2001; Lohmann et al. 2010; Shindell et al. 2013). The difference in the top-ofatmosphere (TOA) radiative budget between the two simulations represents ERF, as climate feedback processes are almost completely suppressed by identically prescribing sea surface temperatures (SSTs) in the two simulations (e.g., Hansen et al. 2005).

Recently, Zelinka et al. (2014) estimated the ERF due to anthropogenic aerosols in fixed-SST experiments by using the approximate partial radiative perturbation (APRP) method of Taylor et al. (2007). They estimated that the total ERF comes from approximately $25 \%$ of aerosol-radiation interaction and from $75 \%$ of aerosolcloud interaction. Aerosol-induced cooling over land and sea ice is likely to affect the atmospheric circulation in fixed-SST simulations, but the resulting changes are expected to be small (Zelinka et al. 2014). Therefore, the aerosol-cloud interaction determined from fixed-SST simulations is mostly irrelevant to aerosol-induced circulation changes occurring in coupled simulations (e.g., Delworth and Dixon 2006; Ocko et al. 2014).

Radiative kernels describe the differential response of TOA radiative fluxes to incremental changes in radiatively important variables and have been widely used in the analysis of climate feedbacks, radiative adjustments, and radiative forcings (e.g., Soden and Held 2006; Soden et al. 2008; Shell et al. 2008; Block and Mauritsen 2013; Vial et al. 2013; Huang and Zhang 2014; Zhang and Huang 2014; Chung et al. 2014). In the next section, we outline a method that uses radiative kernels to quantify the aerosol-mediated cloud response in coupled simulations and use this method to examine the coupled response of clouds and the circulation to aerosol forcing in model simulations from phase 5 of the Coupled Model Intercomparison Project (CMIP5).

\section{b. Methods}

The radiative response of clouds to aerosol forcing is analyzed for two transient climate change experiments of CMIP5 [referred to as historical and representative concentration pathway 4.5 (RCP4.5)]. The historical experiment consists of coupled model integrations forced by historical changes in well-mixed greenhouse gases, aerosols, and other forcing agents over the period 1850-2005. The RCP4.5 experiment is a future climate projection forced with RCPs (Moss et al. 2010) starting from year 2006. The RCP4.5 scenario yields a radiative forcing of approximately $4.5 \mathrm{~W} \mathrm{~m}^{-2}$ by 2100 . Aerosols included in these experiments consist of sulfate aerosols, organic carbon, black carbon, mineral dust, and sea salt. Other types of aerosols and aerosol precursors might also be prescribed in some models.

We also use model integrations from three other scenarios of CMIP5 in which individual forcing agents are prescribed separately. These include the $1 \mathrm{pctCO} 2$, in which the concentration of atmospheric $\mathrm{CO}_{2}$ is increased over a 140 -yr period at a rate of $1 \% \mathrm{yr}^{-1}$, and the historicalGHG and historicalAA, in which the wellmixed anthropogenic greenhouse gases and anthropogenic aerosols from the historical experiment are imposed separately. In addition to these coupled simulations, fixed-SST simulations (i.e., sstClimAerosol) are used to estimate aerosol-induced changes in cloud microphysical properties and to infer dynamical cloud response through comparison with coupled simulations. More detailed information on these climate change scenarios is given in Taylor et al. (2012).

Because the IRF is not archived for these experiments, we estimate the IRF for each scenario using 
TABLE 1. Details of the CMIP5 experiments analyzed in this study.

\begin{tabular}{|c|c|c|c|}
\hline & Name & Purpose & No. of models \\
\hline Exp 1 & historical & $\begin{array}{l}\text { Examine cloud radiative response to increases in } \\
\text { anthropogenic aerosols in multiforcing coupled simulations. }\end{array}$ & 13 \\
\hline Exp 2 & historicalAA & $\begin{array}{l}\text { Examine cloud radiative response to increases in } \\
\text { anthropogenic aerosols in aerosol-only coupled simulations. }\end{array}$ & 7 \\
\hline Exp 3 & historicalGHG & $\begin{array}{l}\text { Examine cloud radiative response to increases in } \\
\text { anthropogenic greenhouse gases in greenhouse-gas-only } \\
\text { coupled simulations. }\end{array}$ & 13 \\
\hline Exp 4 & historical minus historicalGHG & $\begin{array}{l}\text { Evaluate the aerosol-mediated cloud radiative response } \\
\text { derived from exp } 1 .\end{array}$ & 13 \\
\hline Exp 5 & $\mathrm{RCP} 4.5$ & $\begin{array}{l}\text { Examine cloud radiative response to projected decreases } \\
\text { in anthropogenic aerosols in multiforcing coupled simulations. }\end{array}$ & 13 \\
\hline Exp 6 & sstClimAerosol & $\begin{array}{l}\text { Examine cloud radiative response to increases in } \\
\text { anthropogenic aerosols in fixed-SST simulations. }\end{array}$ & 5 \\
\hline Exp 7 & historicalAA minus sstClimAerosol & $\begin{array}{l}\text { Estimate dynamical cloud response driven by aerosol-induced } \\
\text { changes in the atmospheric circulation. }\end{array}$ & 5 \\
\hline
\end{tabular}

clear-sky radiative kernels $K^{0}$ by subtracting the sum of kernel-estimated radiative flux perturbation due to changes in temperature $T$, water vapor $W$, and surface albedo $a$ from model-simulated perturbation $\Delta R^{0}$; that is, IRF $=\Delta R^{0}-\left(K_{T}^{0} \Delta T+K_{W}^{0} \Delta W+K_{a}^{0} \Delta a\right)$. For temperature and water vapor, the product at each pressure level is integrated from the surface to the tropopause.

The TOA radiative flux perturbations resulting from cloud changes (i.e., total cloud radiative response $\left.\Delta R_{C}^{\text {tot }}\right)$ are determined following Soden et al. (2008), in which radiative kernels are used to account for the cloud masking effect of noncloud feedbacks and imposed radiative forcing. We isolate the cloud changes due to $\mathrm{CO}_{2}$ (and other well-mixed greenhouse gases) from those due to aerosols using model output from the 1 pctCO2 scenario by assuming that the total cloud radiative response to greenhouse gas forcing is proportional to global-mean surface warming. For each model, the global-mean surface warming in the historical and RCP4.5 experiments $\bar{T}_{s}$ is multiplied by the cloud radiative response obtained from the corresponding $1 \mathrm{pctCO} 2$ scenario $\alpha_{1 \mathrm{pctCO} 2}$, which is normalized by the corresponding global-mean surface warming. The product is then subtracted from $\Delta R_{C}^{\text {tot }}$ for both the historical and RCP4.5 experiments to yield the aerosol-mediated cloud radiative response $\Delta R_{C}^{\text {aer }}$ for those scenarios (i.e., $\Delta R_{C}^{\mathrm{aer}}=\Delta R_{C}^{\mathrm{tot}}-\alpha_{1 \mathrm{pctCO} 2} \Delta \bar{T}_{s}$ ). In section 3 , we evaluate this method using matching pairs of the historical climate change experiments with aerosol and well-mixed greenhouse gas forcing imposed separately and show that this method accurately captures both the magnitude and distribution of aerosol-mediated cloud changes. Table 1 gives an overview of the analyses conducted in this study, with the analyzed climate models listed in Table S1 in the supplemental material.
Aerosol forcing drives changes in the atmospheric circulation when SSTs are allowed to adjust to the imposed forcing. This implies that the resulting nonlocal dynamical cloud changes in coupled simulations could be considered to be a surface-driven feedback. However, the circulation changes are linked to changes in the hemispheric temperature gradient rather than globalmean temperature changes. This means that the resulting nonlocal dynamical cloud changes could also be classified as a rapid adjustment because many studies define the surface-driven feedback using global-mean temperature changes (e.g., Gregory et al. 2004; Forster and Taylor 2006; Andrews et al. 2012; Forster et al. 2013; Zelinka et al. 2013). For this reason, instead of using the term "adjusted forcing" or "aerosol indirect forcing," we use "aerosol-mediated cloud radiative response" in this study, which includes the nonlocal dynamical cloud changes as well as the aerosol-induced changes in cloud microphysical properties.

\section{Results}

\section{a. Total cloud radiative response and radiative forcing}

Figure 1 displays maps of the multimodel mean total cloud radiative response (normalized by corresponding changes in global-mean surface temperature) for the historical, historicalGHG, RCP4.5, and $1 \mathrm{pctCO} 2$ emission scenarios. These maps highlight the strong dependence of the total cloud radiative response, which is normalized by global warming, to the emission scenario. The total cloud radiative response in the RCP4.5 experiment is mostly positive with negative values restricted to the Southern Ocean and North Atlantic. In contrast, the total cloud radiative response in the 

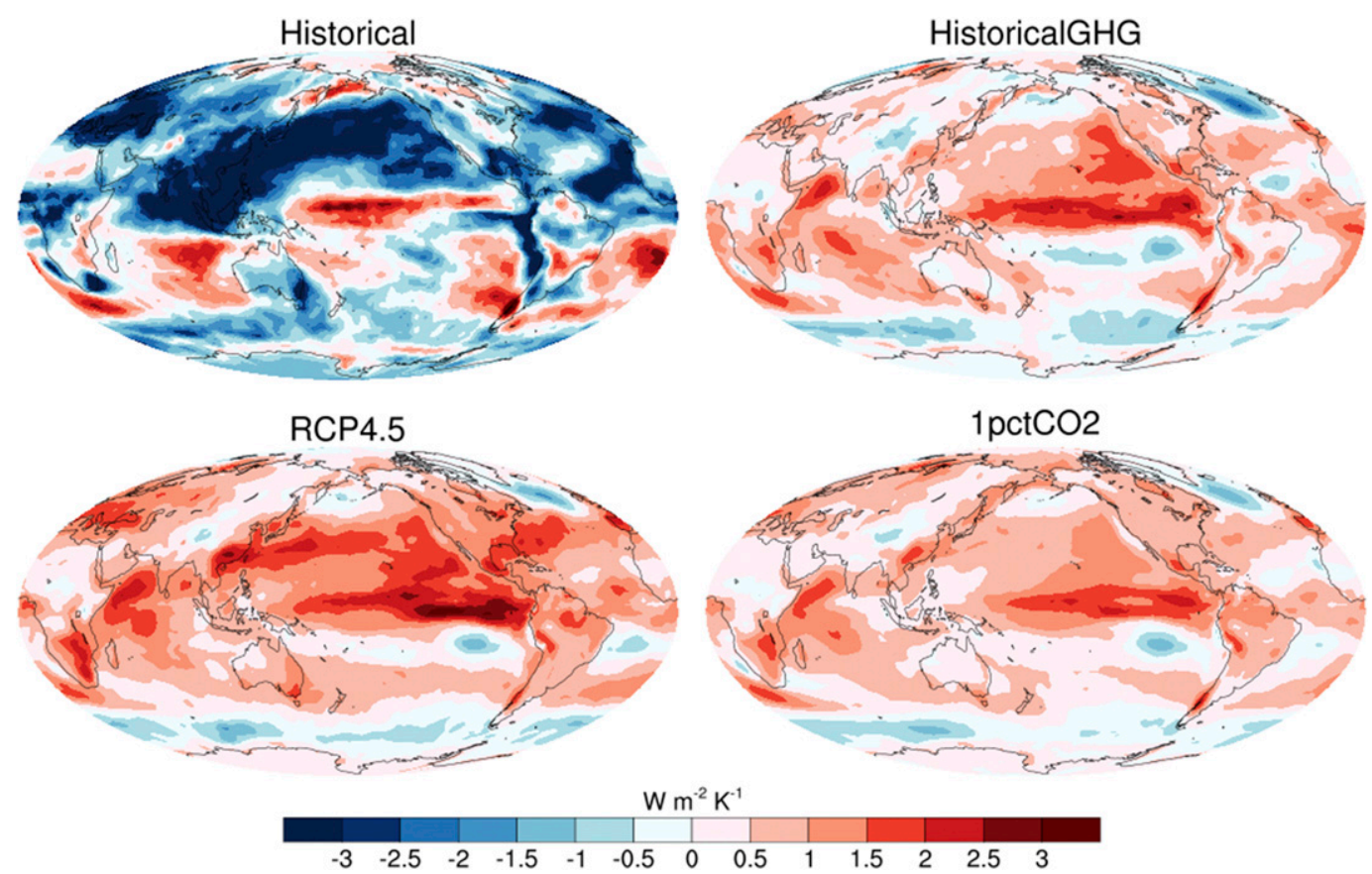

FIG. 1. The multimodel mean cloud radiative response for the (top left) historical, (top right) historicalGHG, (bottom left) RCP4.5, and (bottom right) 1pctCO2 experiments. For all experiments, the differences are computed between the last 20 years of the simulations and the base climate, which is defined as a 20 -yr period of preindustrial control simulations for the historical, historicalGHG, and 1pctCO2 experiments, and the period 1986-2005 of the historical experiment for the RCP4.5 experiment. The change in cloud radiative response for each model is then normalized by the change in global-mean surface temperature before computing the multimodel ensemble mean.

historical experiment exhibits negative values throughout much of the NH. Comparison with the historicalGHG experiment, in which the same models are integrated with historical changes in anthropogenic greenhouse gases alone, verifies that the $\mathrm{NH}$ negative radiative flux perturbations in the historical experiment are primarily related to anthropogenic aerosols.

Since part of the total cloud radiative response results from the global-mean surface warming and rapid cloud adjustment to the $\mathrm{CO}_{2}$ increase, the 1 pctCO2 experiment is used to isolate these components of the total cloud radiative response (Fig. 1, bottom right). Large positive values are found over the equatorial Pacific, southern part of Africa, and northern part of South America, with negative values over the Southern Ocean resulting in hemispheric asymmetry. This spatial pattern is largely similar to that shown in Zelinka et al. (2013, 2016) and Chung and Soden (2015), reflecting the tendency for the cloud feedback to dominate the total cloud radiative response.

Figure 2 presents spatial distributions of the multimodel mean clear-sky radiative forcing for the historical, historicalGHG, and RCP4.5 experiments. For the historical experiment, a negative shortwave forcing extends over East Asia, North America, Europe, and
South Asia, highlighting the impact of increasing anthropogenic aerosols in this scenario. In contrast, these regions exhibit a positive forcing for the RCP4.5 experiment, because of the projected reductions in anthropogenic aerosols and their precursors (e.g., Lamarque et al. 2011; Rotstayn et al. 2013). The clearsky shortwave radiative forcing is weaker and more spatially uniform in the Southern Hemisphere (SH), reflecting the asymmetry in anthropogenic aerosol loadings between the hemispheres. Figure 3 shows the global-mean values of the clear-sky radiative forcing for each model to highlight the intermodel spread in the forcing estimates. The clear-sky shortwave radiative forcing in the historical scenario ranges from -2 to $-0.5 \mathrm{~W} \mathrm{~m}^{-2}$. Accounting for cloud masking effect (Zelinka et al. 2014) results in a range from approximately -1 to $-0.2 \mathrm{~W} \mathrm{~m}^{-2}$, which is comparable to the $5 \%-95 \%$ confidence intervals of the total-sky net aerosol direct forcing (from -0.95 to $+0.05 \mathrm{~W} \mathrm{~m}^{-2}$ ) reported in Myhre et al. (2013). The projected reduction in anthropogenic aerosols in the RCP4.5 experiment produces a similar range of positive clear-sky shortwave radiative forcing.

The clear-sky longwave radiative forcing exhibits a spatially uniform distribution in all three experiments 

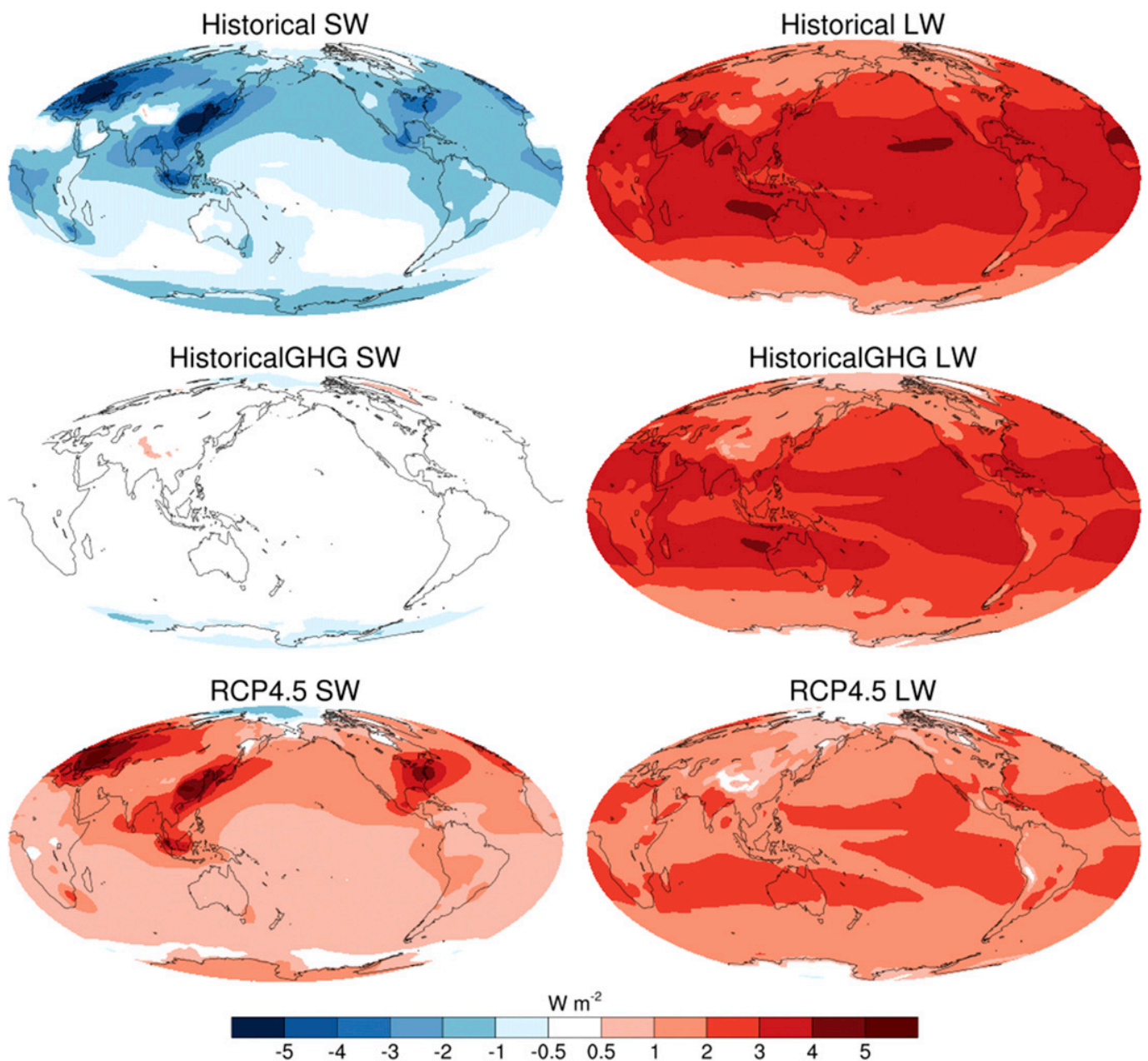

FIG. 2. The multimodel mean clear-sky radiative forcing for the (top) historical, (middle) historicalGHG, and (bottom) RCP4.5 experiments for (left) shortwave and (right) longwave components are shown. The time periods of the base and perturbed climates are the same as in Fig. 1.

(Fig. 2, right). The clear-sky shortwave radiative forcing is nearly zero in the historicalGHG experiment, and the longwave forcing is comparable to that in the historical experiment.

\section{b. Aerosol-mediated cloud radiative response}

In this section, we estimate $\Delta R_{C}^{\text {aer }}$ in the historical [experiment (exp) 1] and RCP4.5 (exp 5) that includes aerosol-induced changes in cloud microphysical properties, semidirect effects through modified static stability of the atmosphere resulting from absorbing aerosols, and cloud changes arising from aerosol-induced changes in the atmospheric circulation. The aerosol-mediated cloud radiative response for the historical experiment (Fig. 4, top left) exhibits negative values over the $\mathrm{NH}$ oceans where the anthropogenic aerosols are frequently transported by westerlies from the source regions (Fig. 2), reflecting the in situ modification of cloud microphysical properties by aerosols (e.g., Twomey 1977; Albrecht 1989; Penner et al. 1992; Rotstayn et al. 2013; Zelinka et al. 2014). On the other hand, part of the SH oceans exhibits positive values where the local emissions of anthropogenic aerosols are negligible compared to the NH. These cloud changes are surprising, both by their sign and their lack of proximity to significant aerosol sources, which suggests that they do not originate from in situ modification by aerosols but rather arise from some other remote mechanism (e.g., Ceppi et al. 2013; Allen et al. 2015). Although the SH responses are smaller compared to the $\mathrm{NH}$ changes, we show below that they play an important role in amplifying the hemispheric contrast in the radiative impact of aerosols.

To verify that the changes estimated from the historical scenario using the radiative kernel method do reflect aerosol-mediated changes in clouds, we compare them 

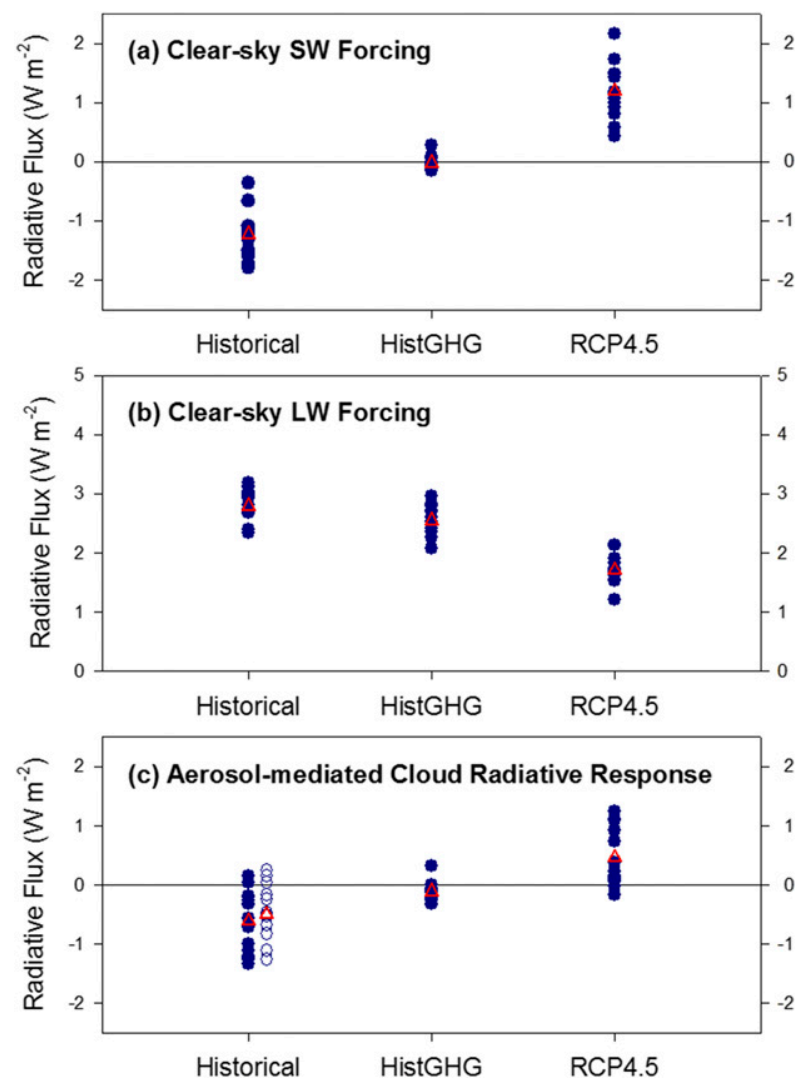

FIG. 3. Intermodel comparison of the global-mean, 20-yr average (a) clear-sky shortwave radiative forcing, (b) clear-sky longwave radiative forcing, and (c) aerosol-mediated cloud radiative response for the historical, historicalGHG, and RCP4.5 experiments. Open circles in (c) denote the aerosol-mediated cloud radiative response for the historical experiment, which is derived by subtracting the cloud-induced radiative flux perturbation in the historicalGHG experiment from that in the historical experiment. The time periods of the base and perturbed climates are the same as in Fig. 1. Each symbol denotes an individual model, with red triangles representing the multimodel mean.

to the cloud radiative response obtained by differencing the historical and historicalGHG experiments (exp 4; Fig. 4, top right) and to the historicalAA simulations (exp 2; Fig. 4, bottom left). All three cases exhibit similar spatial patterns characterized by strongly negative values in the $\mathrm{NH}$ and smaller positive values over part of the SH oceans.

Next, we estimate the aerosol-mediated cloud radiative response under future climate projections. Figure 4 (bottom right) shows the multimodel mean distribution of aerosol-mediated cloud changes in response to the RCP4.5 emission scenario, which prescribes a reduction in anthropogenic aerosols. In this scenario, the spatial pattern of the aerosolmediated cloud radiative response opposes that in the historical scenario, with strongly positive values over the NH oceans and negative values over part of the SH oceans.

Figure $3 \mathrm{c}$ shows the global-mean values of the kernel estimates of aerosol-mediated cloud radiative response for the historical, historicalGHG, and RCP4.5 scenarios. For reference, we also show the global-mean of the cloud radiative response obtained by differencing the historical and historicalGHG experiments (open circles) to demonstrate the validity of the kernel approach. Note the aerosol-mediated cloud response exhibits a substantial intermodel spread in both historical and future scenarios. In a few models, the aerosol-mediated cloud radiative response exhibits small positive values for the historical experiment (negative for the RCP4.5 experiment), in contrast to the corresponding clear-sky shortwave radiative forcing.

The spatial similarity of the estimated aerosolmediated cloud radiative response among exp 1 (historical), exp 2 (historicalAA), and exp 4 (historical minus historicalGHG) lends credence to the use of kernels for estimating the aerosol-mediated cloud radiative response from model simulations integrated with both aerosols and greenhouse gases. However, given that the signal of greenhouse gas forcing is removed based on global-mean temperature, the kernel method might underestimate the magnitude of aerosolmediated cloud radiative response for multiforcing scenarios. This is because the aerosol-induced globalmean temperature changes alter the magnitude of the greenhouse gas-induced warming. As a result, aerosolonly simulations such as the historicalAA scenario are needed to more accurately quantify the response of clouds to projected decreases in anthropogenic aerosols and their precursors.

\section{c. Dynamical cloud changes driven by aerosol forcing}

In this section, we use both coupled and fixed-SST simulations with identical aerosol forcing to separate the aerosol-mediated cloud changes into a microphysical component and a dynamical component. Following Zelinka et al. (2014), the microphysical component is computed by differencing the cloud response in two fixed-SST experiments from CMIP5-one with preindustrial aerosols (i.e., sstClim) and one with aerosols set at present-day levels (i.e., sstClimAerosol). Using fixed-SST simulations inhibits cloud feedbacks associated with ocean surface warming, as well as changes in the atmospheric circulation driven by the asymmetric pattern of warming due to aerosol forcing (Ming and Ramaswamy 2011; Bollasina et al. 2011; Rotstayn et al. 2013; Hwang et al. 2013; Ocko et al. 2014). Since land and sea ice temperatures are not constrained in fixedSST simulations, aerosol-induced surface cooling over 

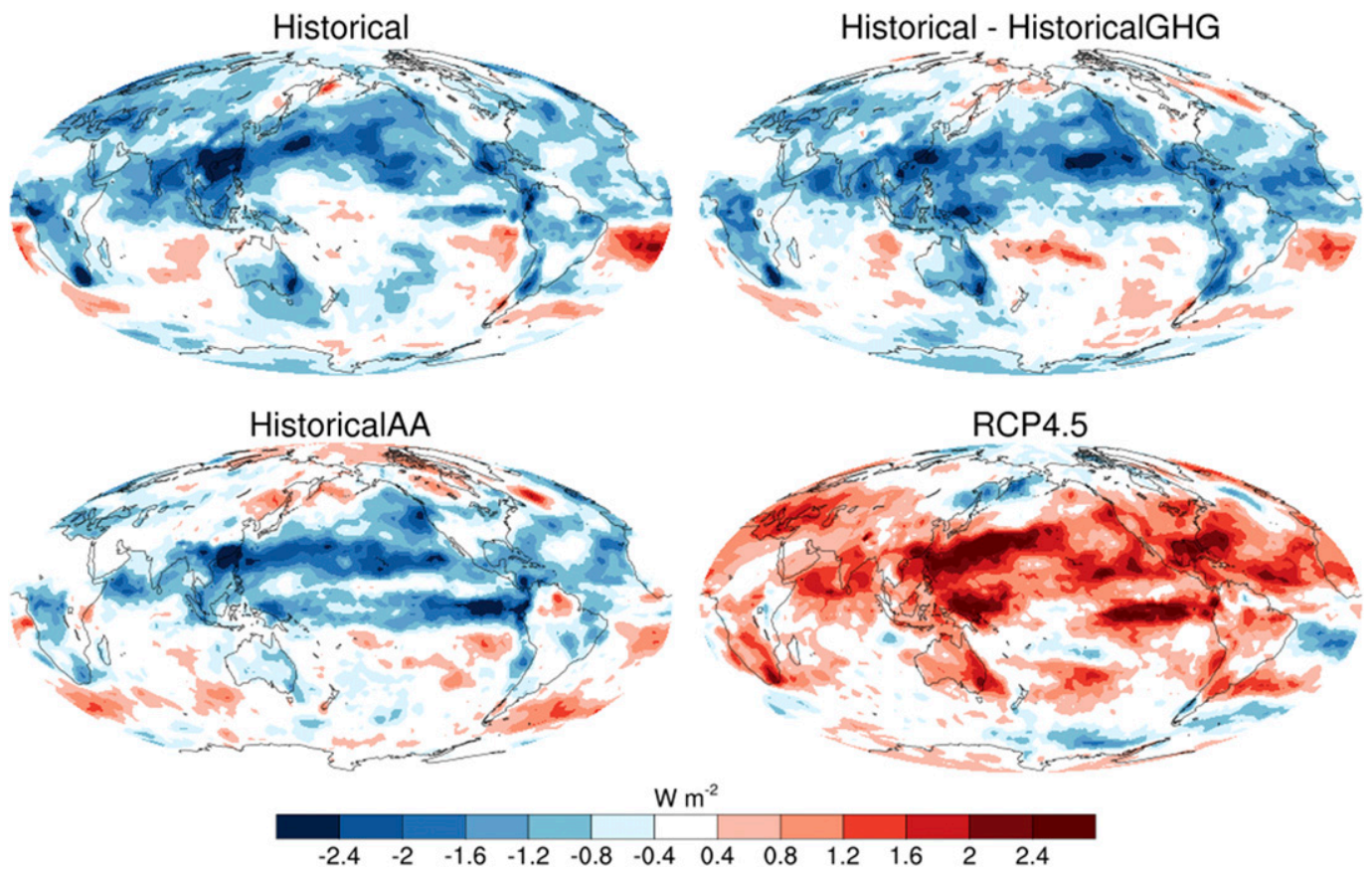

FIG. 4. The multimodel mean aerosol-mediated cloud radiative response in the (top left) historical all-forcing (i.e., historical), (bottom left) historical anthropogenic aerosol-only (i.e., historicalAA), and (bottom right) RCP4.5 experiments. For comparison, (top right) the aerosol-mediated cloud radiative response is displayed for the historical experiment, which is derived by subtracting the cloud-induced radiative flux perturbation in the historicalGHG experiment from that in the historical experiment. The time periods of the base and perturbed climates are the same as in Fig. 1. Seven models, for which the historicalAA simulations are available, are used to compute the multimodel mean.

land and sea ice might affect the atmospheric circulation. However, as will be shown later, the resulting circulation changes are neither distinct nor zonally systematic. As a result, the dynamical component can be estimated by subtracting the cloud response to aerosol forcing in fixed-SST simulations, which includes semidirect effects in addition to microphysical component, from the total aerosol-mediated cloud changes obtained from the coupled model experiments using identical aerosol forcing. The dynamical component estimated in this way may include signals related with local SST changes which are not directly linked to the circulation changes.

Figure 5 compares the multimodel mean aerosolmediated cloud radiative response in coupled simulations (exp 2; Fig. 5, top) with that in fixed-SST simulations (exp 6; Fig. 5, middle) for models for which both simulations are available. The difference (exp 7; Fig. 5, bottom) represents our estimate of the dynamically driven cloud changes due to aerosol forcing. There is a noticeable difference in aerosol-mediated cloud changes between the coupled and fixed-SST simulations. For the coupled model simulations, which include both the dynamical and microphysical changes, the aerosol-mediated response shows large negative values over the $\mathrm{NH}$ where the in situ aerosol forcing is large. In addition there are weaker positive values over the $\mathrm{SH}$ where the in situ aerosol forcing is negligible. In contrast, the fixed-SST experiments, which are dominated by the microphysical changes, exhibit weaker negative values of the $\mathrm{NH}$ and negligible values over the SH oceans. The difference between the coupled and fixed-SST experiments (Fig. 5, bottom) illustrates the contribution of the dynamical cloud changes. The dynamical response to aerosols induces changes in radiative fluxes that are comparable in magnitude to the microphysical response but also enables changes in clouds that are remote from the aerosol forcing itself. These changes act to further amplify the interhemispheric asymmetry of the cloud microphysical response to aerosol forcing by inducing negative cloud radiative changes in the $\mathrm{NH}$ and positive changes in the $\mathrm{SH}$.

\section{d. Aerosol-mediated changes in dynamics and meridional energy transport}

Next, we examine the aerosol-mediated changes in atmospheric circulation and meridional energy transport. As with the aerosol-mediated cloud changes (Fig. 4), our estimates of the aerosol-mediated changes 

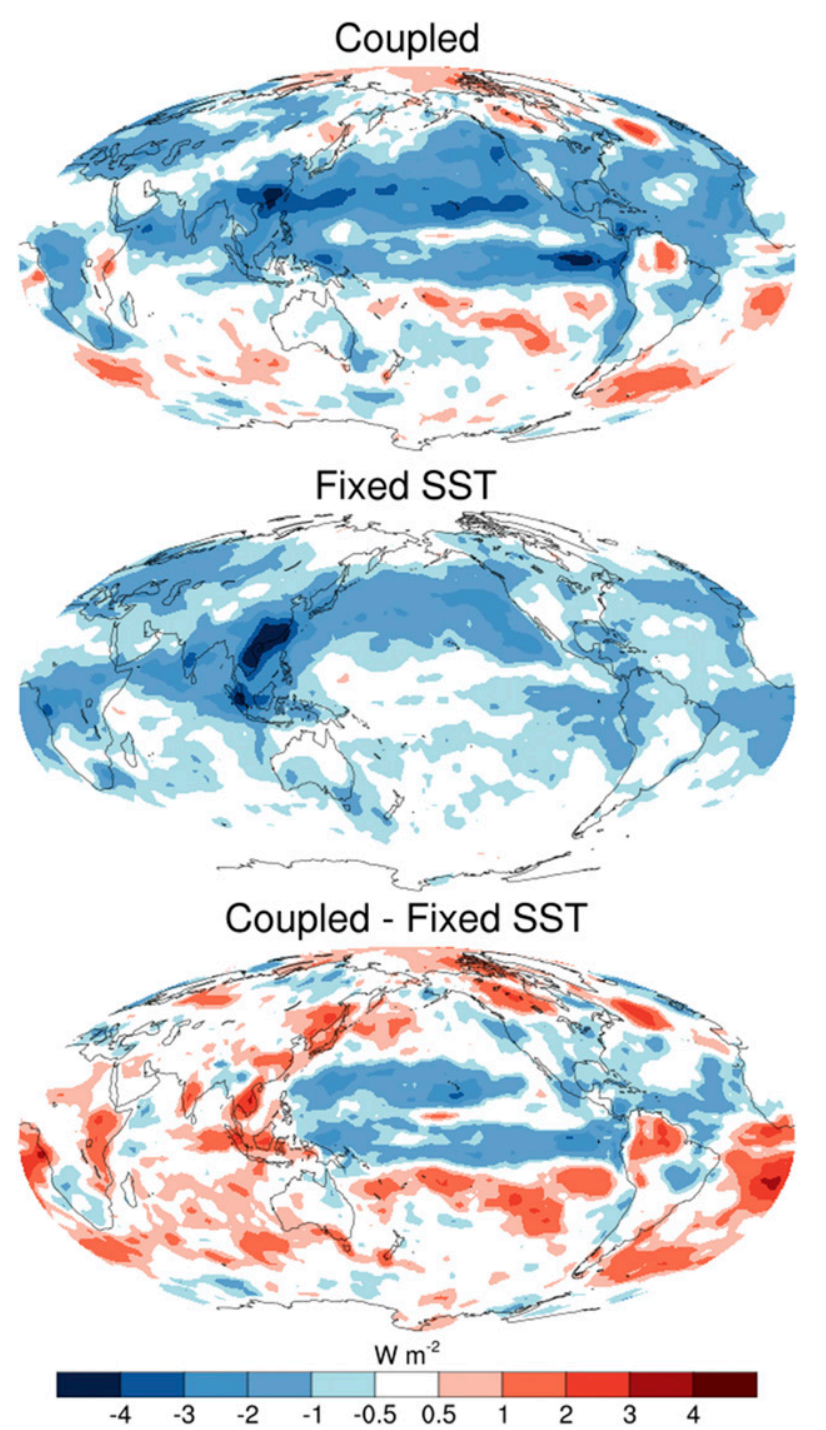

FIG. 5. The multimodel mean aerosol-mediated cloud radiative response in (top) coupled simulations [historicalAA minus preindustrial control (piControl)], which contains both microphysical and dynamical cloud responses to aerosol forcing, and (middle) fixed-SST (sstClimAerosol minus sstClim) simulations, which contains mostly the microphysical cloud response to aerosol forcing. To estimate the dynamical cloud response to historical aerosol forcing, (bottom) the difference (coupled minus fixed SST) between the "microphysical plus dynamical" in (top) and "mostly microphysical" cloud responses in (middle) is shown. The aerosolmediated cloud radiative response for the fixed-SST simulations is adopted from Zelinka et al. (2014).

in the circulation and energy transport for the historical (exp 1) are compared to that obtained by differencing the historical and historicalGHG simulations (exp 4) to evaluate the validity of our methodology.

Figure 6 displays the multimodel mean change in the zonal-mean meridional streamfunction (shading) with contours depicting the zonal-mean circulation in the base climate. Compared to the base climate, the increased anthropogenic aerosols induce anomalous clockwise circulation over the deep tropics in the historical experiment, weakening the ascending branch of the Hadley circulation in the $\mathrm{NH}$ and strengthening it in the $\mathrm{SH}$. This pattern is consistent with that obtained by differencing the historical and historicalGHG experiments (Fig. 6, center) and with that from the historicalAA (exp 2; Fig. 7, top left). The aerosol forcing, however, does not induce noticeable circulation changes in fixedSST runs (exp 6; Fig. 7, top right), confirming that the circulation changes simulated in coupled runs are linked to the modified hemispheric temperature gradient. Corresponding changes in cloud area fraction also differ substantially between the coupled (exp 2$)$ and fixed-SST (exp 6) simulations (Fig. 7, bottom), which is in agreement with their contrast in the circulation changes. Conversely, the reduction in anthropogenic aerosols in the RCP4.5 (exp 5) leads to anomalous counterclockwise circulation over the deep tropics and a strengthening of the NH Hadley circulation. Changes in sea level pressure in response to historical aerosol forcing further illustrate aerosol-driven circulation changes in the SH (Fig. 8). The multimodel mean difference in sea level pressure between the historical and historicalGHG simulations (exp 4) is consistent with the multimodel mean change in sea level pressure in the historicalAA (exp 2), with both showing a reduction in surface pressure in the $\mathrm{SH}$ subtropical oceans, indicating that the circulation changes in the SH subtropical oceans are attributed to the aerosol forcing. As shown below, such changes in zonal-mean circulation are driven by required changes in cross-equatorial energy transport due to the hemispheric asymmetry in aerosol forcing.

It is worth noting the remarkable asymmetry in the circulation changes between the historical (exp 1) and RCP4.5 (exp 5). This is further evident in the zonalmean changes in midtropospheric $(500 \mathrm{hPa})$ vertical velocity (Fig. 9). In response to historical aerosol forcing, anomalous descending (ascending) motion is induced over the $\mathrm{NH}(\mathrm{SH})$ tropics. A nearly identical reversal of this circulation change is noted for the RCP4.5 experiment (note that the sign of the changes in RCP4.5 is reversed to highlight the similarity). This implies that, at least in the zonal mean, the circulation changes are a linear response to the aerosol forcing.

Changes in the zonal-mean energy transport (atmosphere plus ocean) resulting from the aerosol-mediated cloud radiative response are computed by integrating the TOA radiative flux. Resulting meridional distributions indicate that the hemispheric asymmetry in the aerosol-mediated cloud radiative response induces energy transport to compensate the energy imbalance 

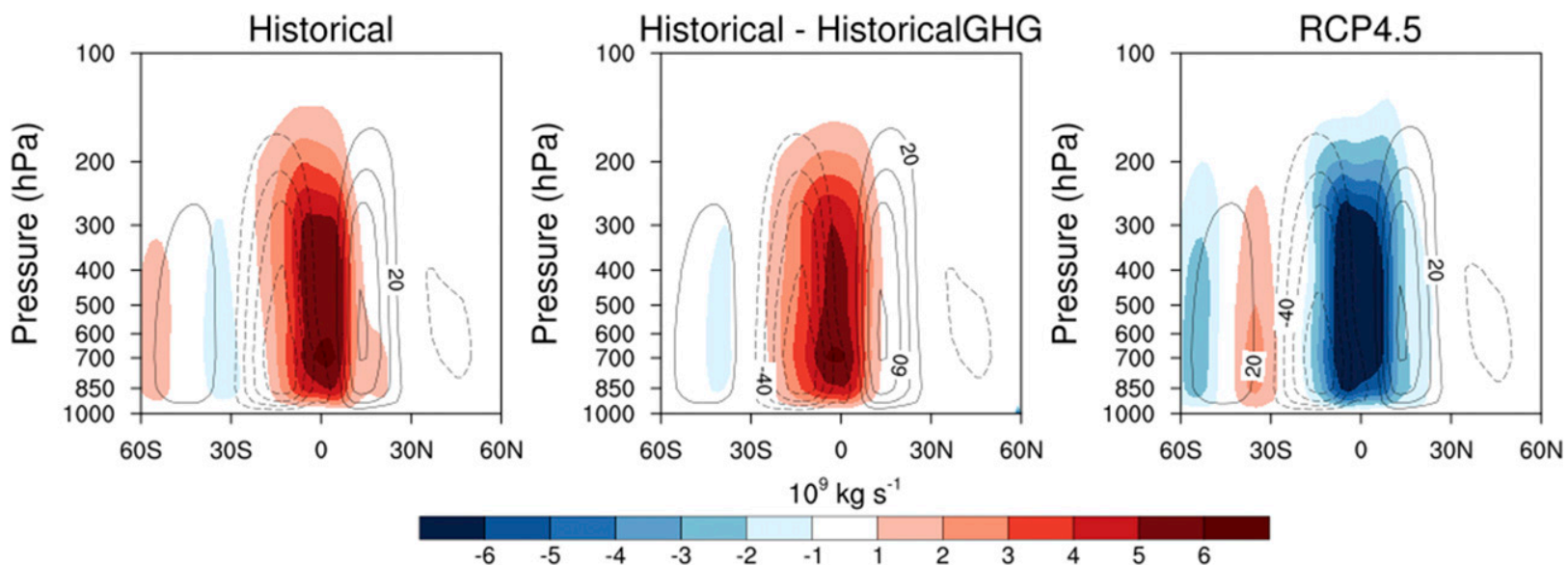

FIG. 6. Multimodel mean of the aerosol-mediated change in the zonal-mean meridional streamfunction $\left(10^{9} \mathrm{~kg} \mathrm{~s}^{-1}\right)$ for the (left) historical and (right) RCP4.5 experiments (color shading). For comparison, (center) the multimodel average of the difference in the zonalmean meridional streamfunction between the historical and historicalGHG experiments is shown. Contours represent the multimodel average zonal-mean meridional streamfunction in the base climate. The sign convention is such that clockwise (counterclockwise) circulation is positive (negative). The time periods of the base and perturbed climates are the same as in Fig. 1.

between the hemispheres (Fig. 10a). Consistent with the meridional displacement of the Hadley circulation, the cross-equatorial energy transport is northward in response to increased aerosols (exp 1 and exp 4) and southward in response to projected reductions in aerosols (exp 5), in agreement with previous studies (e.g., Ming and Ramaswamy 2011; Hwang et al. 2013; Ocko et al. 2014; Huang and Zhang 2014). To evaluate the
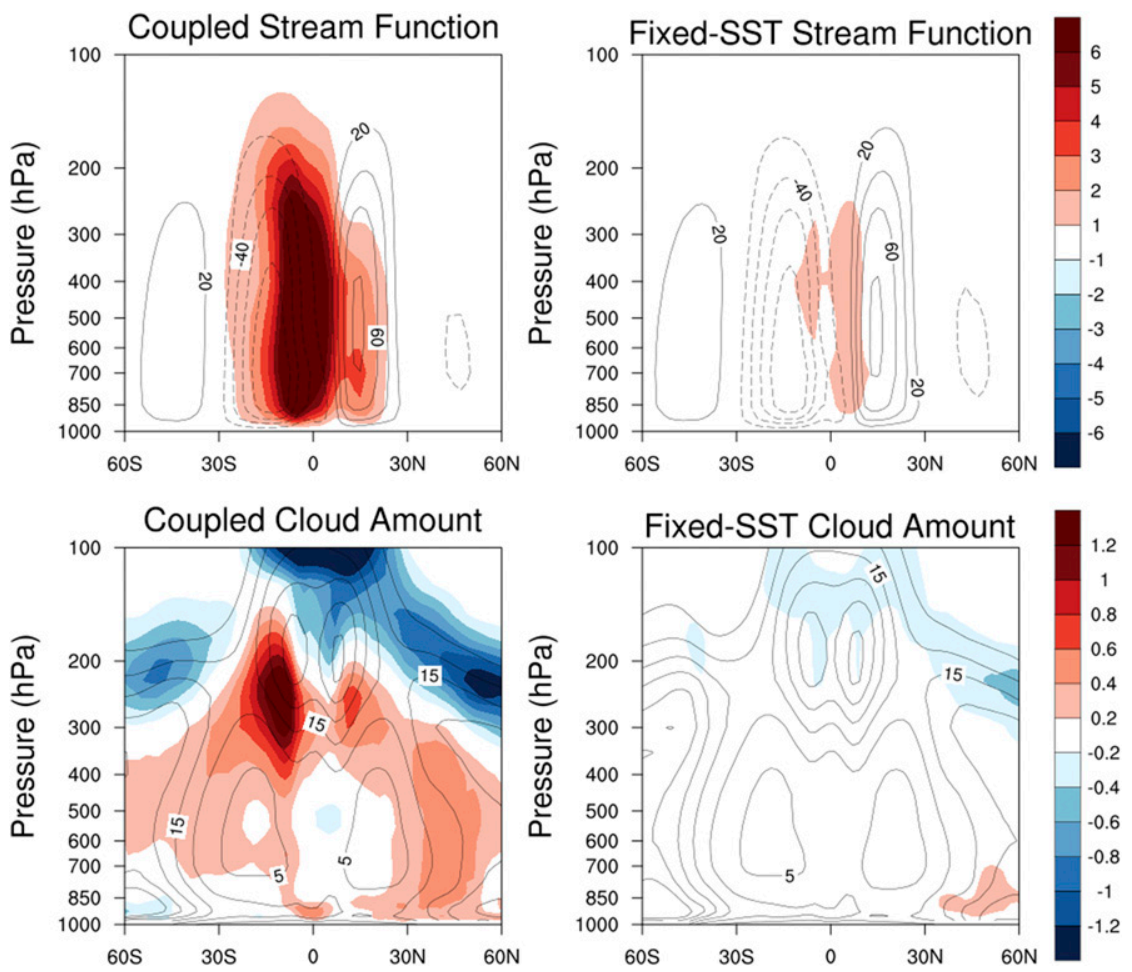

FIG. 7. Multimodel mean changes in the (top) zonal-mean meridional streamfunction $\left(10^{9} \mathrm{~kg} \mathrm{~s}^{-1}\right)$ and (bottom) cloud area fraction (\%) in response to increases in anthropogenic aerosols in (left) coupled (historicalAA minus piControl) and (right) fixed-SST (sstClimAerosol minus sstClim) simulations with contours representing the multimodel average in the base climate. The sign convention for streamfunction is such that clockwise (counterclockwise) circulation is positive (negative). Five models, for which both simulations are available, are used to compute the multimodel mean. 
(a) Historical - HistoricalGHG

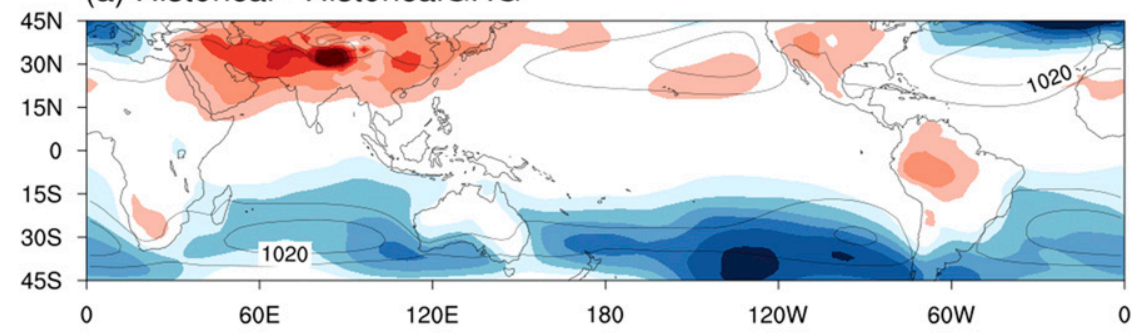

(b) HistoricalAA - piControl

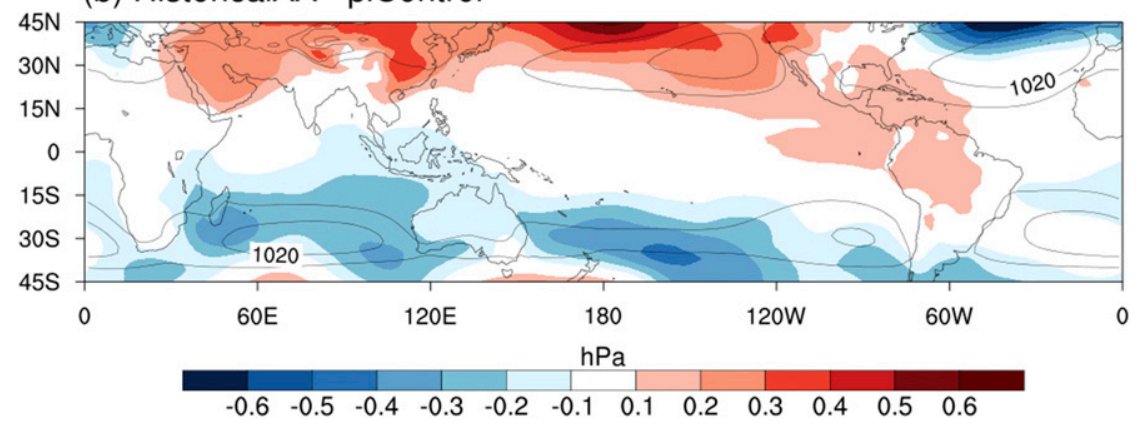

FIG. 8. The multimodel mean changes in sea level pressure $(\mathrm{hPa})$ resulting from historical aerosol forcing in coupled simulations: (a) historical minus historicalGHG and (b) historicalAA minus piControl. Contours represent the multimodel mean sea level pressure in the base climate. The time periods of the base and perturbed climates are the same as in Fig. 1. Seven models, for which the historicalAA simulations are available, are used to compute the multimodel mean.

relative contributions of the microphysical and dynamical cloud changes to the changes in meridional energy transport, Fig. 10b compares the response between the coupled (historicalAA relative to piControl) and fixedSST simulations forced with historical aerosol forcing (exp 7). The impact of the dynamical cloud response is largest in the tropics, where it roughly doubles the crossequatorial energy transport compared to simulations with just microphysical cloud changes and substantially enhances the intermodel spread in the meridional energy transport.

\section{Summary}

Aerosols have long been known to play an important role in altering cloud radiative properties through in situ modification of cloud microphysical processes (e.g., Twomey 1977; Albrecht 1989; Penner et al. 1992; Rotstayn et al. 2013; Zelinka et al. 2014). More recent studies have emphasized the role that the asymmetric pattern of aerosol forcing has in altering the largescale circulation of the atmosphere (e.g., Ming and Ramaswamy 2011; Bollasina et al. 2011; Rotstayn et al. 2013; Hwang et al. 2013; Ocko et al. 2014). In this study, we use radiative kernels to quantify both the instantaneous clear-sky radiative forcing by aerosols and the aerosol-mediated cloud radiative response in coupled model simulations. The method was evaluated using matching pairs of historical climate change simulations with and without aerosol forcing and shown to accurately estimate both the spatial pattern and

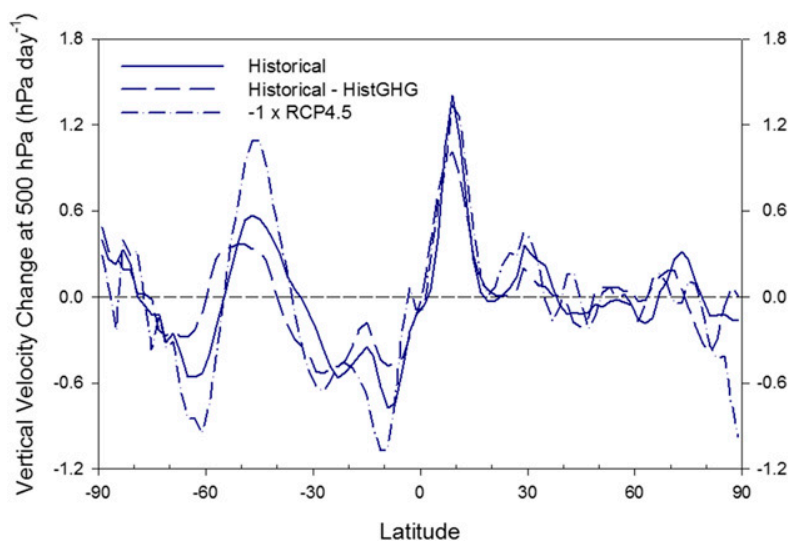

FIG. 9. Multimodel mean of the zonal-mean change in 500-hPa pressure vertical velocity due to historical (solid line) and future (dash-dotted line) aerosol forcing. The sign is reversed for the RCP 4.5 experiment by multiplying by -1 . For comparison, the difference between the historical and historicalGHG experiments is also presented (dashed line). The time periods of the base and perturbed climates are the same as in Fig. 1. 

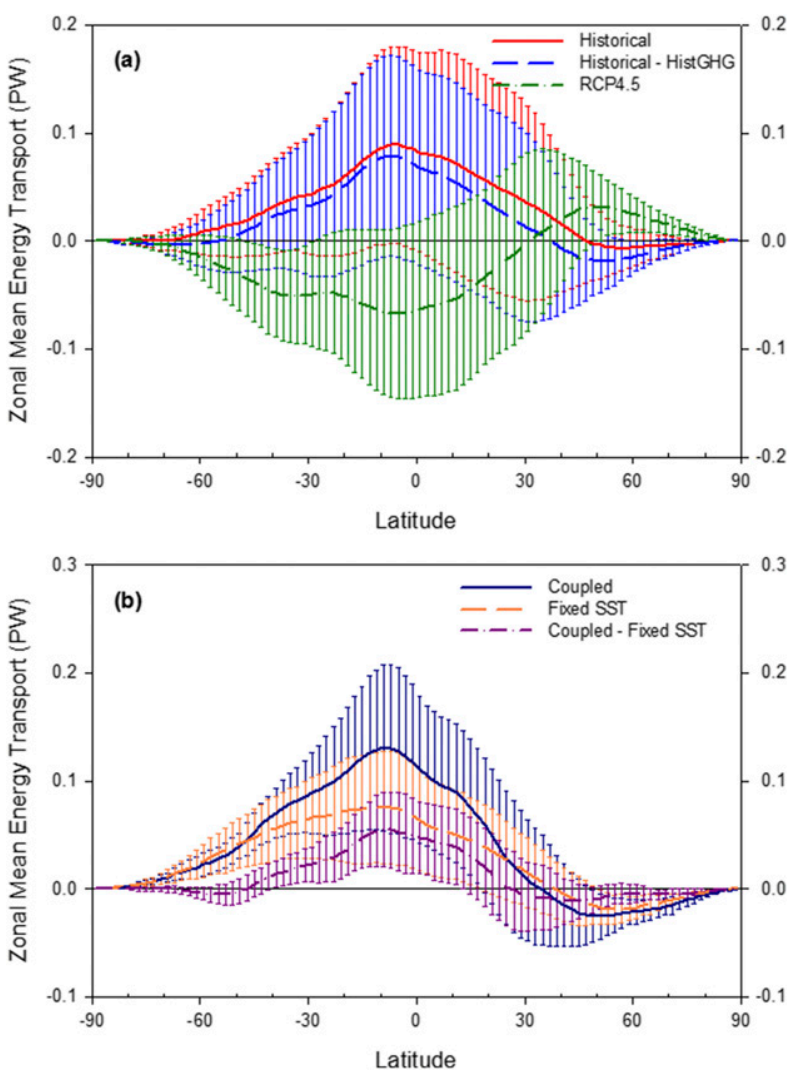

FIG. 10. (a) Changes in the zonal-mean energy transport resulting from aerosol-mediated cloud radiative response in the historical (relative to piControl) and RCP4.5 (relative to historical) experiments. For comparison, the aerosol-mediated cloud radiative response obtained by differencing the historical and historicalGHG experiments is also used to compute the zonal-mean energy transport (blue). The time periods of the base and perturbed climates are the same as in Fig. 1. (b) Changes in the zonal-mean energy transport resulting from aerosol-mediated cloud radiative response in coupled (historicalAA relative to piControl) and fixed-SST (sstClimAerosol relative to sstClim) simulations and the difference between the coupled and fixed-SST simulations (purple). Note that this is a different subset of models than in (a). The sign convention for (a) and (b) is such that northward (southward) transport is positive (negative). Lines and vertical error bars denote multimodel mean and plus or minus one intermodel standard deviation, respectively. The unit of zonalmean energy transport is in petawatt $\left(1 \mathrm{PW}=10^{15} \mathrm{~W}\right)$.

global-mean effects of aerosol forcing and aerosolmediated cloud radiative response.

Our analysis of coupled model simulations from CMIP5 demonstrates how the aerosol-mediated change in the atmospheric circulation induces additional, dynamically driven cloud changes whose radiative impact is comparable to that resulting from in situ changes in cloud microphysical properties, which is inhibited in fixed-SST simulations. This dynamically induced cloud response further amplifies the hemispheric asymmetry of the aerosol forcing for both historical and future emission scenarios. The increased hemispheric asymmetry, in turn, further enhances the cross-equatorial energy transport as well as the intermodel spread in energy transport. These results serve to highlight the important coupling between aerosol-mediated changes in the atmospheric circulation and their role in modulating cloud radiative effects, which serve to further amplify the hemispheric contrast in the radiative impact of aerosols.

Acknowledgments. We acknowledge the World Climate Research Programme's Working Group on Coupled Modelling, which is responsible for CMIP, and we thank the climate modeling groups (listed in Table S1) for producing and making available their model output. For CMIP the U.S. Department of Energy's Program for Climate Model Diagnosis and Intercomparison provides coordinating support and led development of software infrastructure in partnership with the Global Organization for Earth System Science Portals. We thank three anonymous reviewers and editor for their constructive and valuable comments, which led to an improved version of the manuscript. This research was supported by Grants NNX16AH37G and NNX14AB19G from the NASA ROSES program.

\section{REFERENCES}

Albrecht, B. A., 1989: Aerosols, cloud microphysics, and fractional cloudiness. Science, 245, 1227-1230, doi:10.1126/ science.245.4923.1227.

Allen, R. J., A. T. Evan, and B. B. B. Booth, 2015: Interhemispheric aerosol radiative forcing and tropical precipitation shifts during the late twentieth century. J. Climate, 28, 8219-8246, doi:10.1175/JCLI-D-15-0148.1.

Andrews, T., and P. M. Forster, 2008: $\mathrm{CO}_{2}$ forcing induces semidirect effects with consequences for climate feedback interpretations. Geophys. Res. Lett., 35, L04802, doi:10.1029/ 2007 GL032273.

— J. M. Gregory, M. J. Webb, and K. E. Taylor, 2012: Forcing, feedbacks and climate sensitivity in CMIP5 coupled atmosphere-ocean climate models. Geophys. Res. Lett., 39, L09712, doi:10.1029/2012GL051607.

Block, K., and T. Mauritsen, 2013: Forcing and feedback in the MPI-ESM-LR coupled model under abruptly quadrupled $\mathrm{CO}_{2}$. J. Adv. Model. Earth Syst., 5, 676-691, doi:10.1002/ jame.20041.

Bollasina, M. A., Y. Ming, and V. Ramaswamy, 2011: Anthropogenic aerosols and the weakening of the South Asian summer monsoon. Science, 334, 502-505, doi:10.1126/science.1204994.

Ceppi, P., Y.-T. Hwang, X. Liu, D. M. W. Frierson, and D. L. Hartmann, 2013: The relationship between the ITCZ and the Southern Hemispheric eddy-driven jet. J. Geophys. Res. Atmos., 118, 5136-5146, doi:10.1002/jgra.50440.

Chung, E.-S., and B. J. Soden, 2015: An assessment of direct radiative forcing, radiative adjustments, and radiative feedbacks 
in coupled ocean-atmosphere models. J. Climate, 28, 41524170, doi:10.1175/JCLI-D-14-00436.1.

,,- B. J. Sohn, and L. Shi, 2014: Upper-tropospheric moistening in response to anthropogenic warming. Proc. Natl. Acad. Sci. USA, 111, 11 636-11 641, doi:10.1073/pnas.1409659111.

Colman, R. A., and B. J. McAvaney, 2011: On tropospheric adjustment to forcing and climate feedbacks. Climate Dyn., 36, 1649-1658, doi:10.1007/s00382-011-1067-4.

Delworth, T. L., and K. W. Dixon, 2006: Have anthropogenic aerosols delayed a greenhouse gas-induced weakening of the North Atlantic thermohaline circulation? Geophys. Res. Lett., 33, L02606, doi:10.1029/2005GL024980.

Forster, P. M., and K. E. Taylor, 2006: Climate forcings and climate sensitivities diagnosed from coupled climate model integrations. J. Climate, 19, 6181-6194, doi:10.1175/JCLI3974.1.

, T. Andrews, P. Good, J. M. Gregory, L. S. Jackson, and M. Zelinka, 2013: Evaluating adjusted forcing and model spread for historical and future scenarios in the CMIP5 generation of climate models. J. Geophys. Res. Atmos., 118, 11391150, doi:10.1002/jgrd.50174.

Gregory, J. M., and M. Webb, 2008: Tropospheric adjustment induces a cloud component in $\mathrm{CO}_{2}$ forcing. J. Climate, 21, 5871, doi:10.1175/2007JCLI1834.1.

— forcing and climate sensitivity. Geophys. Res. Lett., 31, L03205, doi:10.1029/2003GL018747.

Hansen, J., and Coauthors, 2005: Efficacy of climate forcings. J. Geophys. Res., 110, D18104, doi:10.1029/2005JD005776.

Huang, Y., and M. Zhang, 2014: The implication of radiative forcing and feedback for meridional energy transport. Geophys. Res. Lett., 41, 1665-1672, doi:10.1002/2013GL059079.

Hwang, Y.-T., D. M. W. Frierson, and S. M. Kang, 2013: Anthropogenic sulfate aerosol and the southward shift of tropical precipitation in the late 20th century. Geophys. Res. Lett., 40, 2845-2850, doi:10.1002/grl.50502.

Kamae, Y., M. Watanabe, T. Ogura, M. Yoshimori, and H. Shiogama, 2015: Rapid adjustments of cloud and hydrological cycle to increasing $\mathrm{CO}_{2}$ : A review. Curr. Climate Change Rep., 1, 103-113, doi:10.1007/s40641-015-0007-5.

Lamarque, J.-F., G. P. Kyle, M. Meinshausen, K. Riahi, S. J. Smith, D. P. van Vuuren, A. J. Conley, and F. Vitt, 2011: Global and regional evolution of short-lived radiatively-active gases and aerosols in the representative concentration pathways. Climatic Change, 109, 191-212, doi:10.1007/s10584-011-0155-0.

Lohmann, U., and Coauthors, 2010: Total aerosol effect: Radiative forcing or radiative flux perturbation? Atmos. Chem. Phys., 10, 3235-3246, doi:10.5194/acp-10-3235-2010.

Ming, Y., and V. Ramaswamy, 2011: A model investigation of aerosol-induced changes in tropical circulation. J. Climate, 24, 5125-5133, doi:10.1175/2011JCLI4108.1.

Moss, R. H., and Coauthors, 2010: The next generation of scenarios for climate change research and assessment. Nature, 463, 747756, doi:10.1038/nature08823.

Myhre, G., and Coauthors, 2013: Anthropogenic and natural radiative forcing. Climate Change 2013: The Physical Science
Basis, T. F. Stocker et al., Eds., Cambridge University Press, 659-740.

Ocko, I. B., V. Ramaswamy, and Y. Ming, 2014: Contrasting climate responses to the scattering and absorbing features of anthropogenic aerosol forcings. J. Climate, 27, 5329-5345, doi:10.1175/JCLI-D-13-00401.1.

Penner, J. E., R. E. Dickinson, and C. A. O'Neill, 1992: Effects of aerosol from biomass burning on the global radiation budget. Science, 256, 1432-1434, doi:10.1126/science.256.5062.1432.

Rotstayn, L. D., and J. E. Penner, 2001: Indirect aerosol forcing, quasi forcing, and climate response. J. Climate, 14, 2960-2975, doi:10.1175/1520-0442(2001)014<2960:IAFQFA>2.0.CO;2.

- M. A. Collier, A. Chrastansky, S. J. Jeffrey, and J.-J. Luo, 2013: Projected effects of declining aerosols in RCP4.5: Unmasking global warming? Atmos. Chem. Phys., 13, $10883-$ 10 905, doi:10.5194/acp-13-10883-2013.

Shell, K. M., J. T. Kiehl, and C. A. Shields, 2008: Using the radiative kernel technique to calculate climate feedbacks in NCAR's Community Atmospheric Model. J. Climate, 21, 2269-2282, doi:10.1175/2007JCLI2044.1.

Shindell, D. T., and Coauthors, 2013: Radiative forcing in the ACCMIP historical and future climate simulations. Atmos. Chem. Phys., 13, 2939-2974, doi:10.5194/acp-13-2939-2013.

Soden, B. J., and I. M. Held, 2006: An assessment of climate feedbacks in coupled ocean-atmosphere models. J. Climate, 19, 3354-3360, doi:10.1175/JCLI3799.1.

_ radiative kernels. J. Climate, 21, 3504-3520, doi:10.1175/ 2007JCLI2110.1.

Stevens, B., and S. Bony, 2013: What are climate models missing? Science, 340, 1053-1054, doi:10.1126/science.1237554.

Taylor, K. E., and Coauthors, 2007: Estimating shortwave radiative forcing and response in climate models. J. Climate, 20, 25302543, doi:10.1175/JCLI4143.1.

_ R. J. Stouffer, and G. A. Meehl, 2012: An overview of CMIP5 and the experiment design. Bull. Amer. Meteor. Soc., 93, 485498, doi:10.1175/BAMS-D-11-00094.1.

Twomey, S., 1977: The influence of pollution on the shortwave albedo of clouds. J. Atmos. Sci., 34, 1149-1152, doi:10.1175/ 1520-0469(1977)034<1149:TIOPOT>2.0.CO;2.

Vial, J., J.-L. Dufresne, and S. Bony, 2013: On the interpretation of inter-model spread in CMIP5 climate sensitivity estimates. Climate Dyn., 41, 3339-3362, doi:10.1007/s00382-013-1725-9.

Zelinka, M. D., and Coauthors, 2013: Contributions of different cloud types to feedbacks and rapid adjustments in CMIP5. J. Climate, 26, 5007-5027, doi:10.1175/JCLI-D-12-00555.1.

—, T. Andrews, P. M. Forster, and K. E. Taylor, 2014: Quantifying components of aerosol-cloud-radiation interactions in climate models. J. Geophys. Res. Atmos., 119, 7599-7615, doi:10.1002/2014JD021710.

_ C. Zhou, and S. A. Klein, 2016: Insights from a refined decomposition of cloud feedbacks. Geophys. Res. Lett., 43, 92599269, doi:10.1002/2016GL069917.

Zhang, M., and Y. Huang, 2014: Radiative forcing of quadrupling $\mathrm{CO}_{2}$. J. Climate, 27, 2496-2508, doi:10.1175/JCLI-D-13-00535.1. 